\title{
Research on the Speed Skaters' Rational Nutrition based on Scientific Training
}

\author{
Yuchun Huang*
}

Department of Physical Education, Henan University of Technology, Henan, P.R. China

\begin{abstract}
In the course of training, organic combination of nutrition and training methods is an effective mean of controlling athletes' weight and is significant for improving their physical power. The paper suggests that monitoring the body fat with some nutrition methods of evaluating the body fat, reasonably making the meals and supplying the sports nutrition, controlling the body fat by establishing a standard of well weight in training, adjusting the athletic loads. In the course of properly controlling the weight, it should pay attention to develop well dietary habit, set up better nutritive structure, and hold the depth of combining the weight control with regular training plan. The above suggestions are to build a well base for athletes taking advantage of athletic potential in competition and improving their competitive results
\end{abstract}

Keywords: Speed skater, sports nutrition, scientific training, monitoring, body fat.

\section{INTRODUCTION}

The demands of modern competitive sports on athletes' physical strength, energy, energy mobilization, muscle strength and nerve reflex are higher and higher, success differs from failure only depends on a few percent seconds or a few centimeters, the performance of sports have been more and more close to the limitation of human movement ability $[1,2]$. In this case, if players want to create a good result, they must be engaged in the training of the maximum limit, fully exert their maximum potential, so as to adapt to the development of modern sports science.

In the midst of modern sports science, sports nutrition has become one of the important aspects, without the guarantee of powerful nutrients basis it is unlikely to attach the anticipated targets, at the same time also can't guarantee the effects of training and the health of the body, it has become a consensus of sports science at present. Weight is reflect the development degree of human bones, muscles and obesity index, is also an indicator which reflects the human figure. From the perspective of the physiology weight refers to the total weight of body composition. Body composition refers to the total of the body tissues and organs composition, its physical composition model consist of body fat (fat mass index) and fat free mass index (lean body mass) these two parts namely the weight $=$ to fat weight + body fat. Among them, fat free mass index is consist of muscle, bones, organs, body fluid and skin and other fat free mass. Body composition is usually expressed as a percentage of body fat, namely body fat percentage weight $\times 100 \%=$ body fat weight, Based on the theory of the current sports nutrition research result, the research on the relationship between the body fat percentage and movement ability shows that the size of the body fat percentage, has important significance on developing the special power, less body fat, is advantageous to the athlete muscle strength training and development [Feng et al., 2003]. The research take the point that fat mass and lean body mass are closely related to the sport performance, from mechanics point of view, high body fat increases body size and the amount of the non-force produced material in the body, increased the resistance of the air and sea ice in the taxi, resulting in the slow movement speed. From the metabolism point of view, the burden of too much body fat increased load, increase the consumption of oxygen and energy, reduce the cardiopulmonary function and aerobic capacity, and the fat cells and adipose tissue itself does not directly generate ATP (adenosine triphosphate) biochemical energy, which affect the performance. Only reasonable body composition suitable for fat content and removal of the fat weight will have good effects on athletic ability. So the overmuch body fat of speed skaters is one of the reasons that our speed skating performances are difficult to reach the world advanced level.

\section{REASONABLE NUTRITION AND BODY FAT CONTROL}

Chinese speed skater body fat compared with good speed skating athletes in the world is definitely too high, especially the female athletes. And the high side of body fat has direct relationship with dietary pattern, eating habits and training means in our country.

The reasonable nutrition is one of the important factors on promoting sport ability of athletes, although nutrition is no substitute for training, but the nutrition and other auxiliary hand sections combined with training, which will be beneficial to the improvement of the sports ability, therefore, research and rational diet and nutritional status of athletes to guide the reasonable arrangement of meals, athletes to guar- 
antee reasonable nutrition, athletes have important theoretical and practical significance. Reasonable nutrition means people need all kinds of nutrients, can be satisfied in the daily diet, not only the quantity accord with human body needs, and maintained between various nutrients for human body need reasonable proportion of [3, 4]. Wang Gang [5] found that the existence of the high fat diet, high protein, low carbohydrate nutrition imbalance, so that affects the physiological and biochemical functions, and leads to some athletes high serum cholesterol, urea, creatinine, affects the physiological function and form, and give full play to the movement through the winter Heilongjiang project athletes training center speed skater dietary survey. The results of survey of 91 ice-snow athletes by Chenrui in 1998 showed that the dietary sugar intake accounts for $32 \% \sim 47 \%$ of total energy, fat intake by $43 \% \sim 51 \%$ of total energy. These data suggest that the dietary carbohydrate energy is too low, and the fat high powered nutritional imbalance exist in domestic athlete.

During the period of preparation for the 19th Olympic winter games, sports nutrition group of countries Home short track speed skating athletes dietary nutrition, survey found that athletes heat and staple food (carbohydrates) are inadequate intake, significantly lower than the recommended intake of $3700 \sim 3700 \mathrm{kcal} /$ day and sugar power should be $55 \% \sim 60 \%$ of total heat requirements; The intake of fat and protein is relatively more; as Calorie breakfast meals heat distribution is not reasonable, and is apparent lack of dinner intake on the high side; The main intake of certain vitamins and minerals is inadequate [6].

In recent years, in order to excavate the potential of athletes the speed skating team in Europe and USA also into a large science and technology, in addition to equipment and clothing on continuous innovation, advanced physiological and biochemical monitoring instrument and more effective nutritional recovery methods were applied to the training thought [Shang et al., 2006], there is a close relationship between nutrition and the training of the athletes, teams in Europe and the United States and China in these areas have a large gap.

Sweating a lot in the movement, the large numbers of electrolytes such as potassium, calcium, sodium, magnesium, vitamin and amino acid in bodies of drain outside with sweat, which makes the body fluids, especially blood plasma reducing capacity, and easy to make the athletes' physical strength greatly decrease, depression, athletic ability. Loss of iron content in speed skating athletes training is twice as that of normal, but the iron absorption is only half of the average level, inadequate intake of iron, easy to cause motility iron deficiency and iron deficiency anemia. During sports, the body consumes lots of energy, and the speed of the main energy in the glycolysis endurance events, sports acid metabolites accumulation, will make the ph. inside the body rise, disturb the body acid-base balance, fatigue is difficult to eliminate athletes sweat on the athletic field, hard work, continuously break through physiological limits, is to challenge their own process. And athletes reasonable nutrition supplement, strong body is the foundation of creating excellent grades. Therefore, the athletes have its special requirements on the choice of food and nutrition supply. Chinese speed skater dietary survey shows that the proportions of athletes intake of fat, protein are big, and the proportion of sugar is small, long-term adherence to the consequences of this diet is self-evident. Aerobic training in training base is not solid, burn fat enough training proportion and so on, are likely to be the causes of this result. So to take effective measures to reverse this situation is very necessary.

\subsection{The Evaluation and Monitoring of Body Fat}

Based on survey data of 2000 and 2003, 2 times on Heilongjiang province of dietary nutrition, the group had a system and comprehensive research on the excellent speed skaters in 2006 for the third time to comprehensive dietary nutrition, evaluation of athletes dietary nutrition status. Through physiological, biochemical monitor and blood urine test to acquaintance the status of the function of the body's metabolism and body composition determined to assess athletes body fat levels, reasonably guide the arrangement of the dietary, to make the athletes get ideal body fat [7-9].

The respondents of this group are outstanding speed skaters in Heilongjiang province, training terms all in $6 \sim 12$ years, are all national athlete level athletes, the daily 3 meals for athletes are the buffet forms, using food weighing method and the method of $24 \mathrm{~h}$ review combined. For athletes three meals a day for three days weighing method is adopted to improve the dietary nutrition survey, daily meals during the period of investigation will investigate object, including snacks, all kinds of food consumption, and 3 meals of ripe weight and quantity of food for each meal weighing accurately, and make detailed records. Use 《The application analysis and management system of athletes and the public dietary》 compiled by the State Sports General Administration Institute of Sports Medicine to data processing software for data analysis, calculation, comparing with athletes recommend appropriate energy intake, understand the nutritional status of speed skating athletes and the three major nutrients ratio of heat [10]. And proceed respondents and physiological and biochemical and body fat for athletes test before daily meals, and conduct a comprehensive grasp from various angles under the condition of normal diets and regular trainings of metabolism and function. Specific monitoring contents are shown in Table $\mathbf{1}$.

\subsection{Reasonable Dietary Nutrition Arrangement}

Among modern sports science, sports nutrition has become one of the important aspects, without strong nutrition material basis for security can't achieve anticipated goal, at the same time also can't guarantee the effect of training and the health of the body, this has become a consensus of sports science at present. The so-called nutrients, in addition to reasonable dietary supplements, also need to have the help of sports nutrition food. If athletes with a sports car, athletes' dietary nutrition compared to the high quality gasoline, sports nutrition food, is to join the engine of the propellants. As accelerant can make the engine produces the power, sports nutrition food can help athletes take more training volume and training intensity, after the training as soon as possible to eliminate fatigue, physical stamina quickly recover, make their exercise capacity can be in the game. 
Table 1. Group investigation structure details.

\begin{tabular}{|c|c|}
\hline $\begin{array}{c}\text { Monitoring } \\
\text { type }\end{array}$ & The Specific Content \\
\hline \hline $\begin{array}{c}\text { Energy } \\
\text { intake }\end{array}$ & Total daily energy intake, energy intake of meals \\
\hline $\begin{array}{c}\text { Vitamins } \\
\text { and miner- } \\
\text { als }\end{array}$ & $\begin{array}{c}\text { Retinol equivalent, VB1, VB2, niacin, VC, VE, potassium, } \\
\text { sodium, calcium, magnesium, iron, zinc, selenium }\end{array}$ \\
\hline $\begin{array}{c}\text { All kinds of } \\
\text { food }\end{array}$ & $\begin{array}{c}\text { Sugar (grain), vegetables, fruits, livestock meat, poultry, } \\
\text { aquatic products, eggs, milk, beans, edible oils and fats }\end{array}$ \\
\hline $\begin{array}{c}\text { The bio- } \\
\text { chemical } \\
\text { indicators }\end{array}$ & $\begin{array}{c}\text { Total protein, albumin, total cholesterol, triglyceride, high } \\
\text { density lipid, protein, cholesterol, blood urea, creatinine, } \\
\text { blood testosterone, serum glucose }\end{array}$ \\
\hline $\begin{array}{c}\text { Routine } \\
\text { blood indi- } \\
\text { cators }\end{array}$ & $\begin{array}{c}\text { White blood cells, red blood cells, hemoglobin, red blood } \\
\text { cells deposited, platelet count, calcium, phosphorus, potas- } \\
\text { sium, sodium and chloride }\end{array}$ \\
\hline $\begin{array}{c}\text { Body fat } \\
\text { composition }\end{array}$ & $\begin{array}{c}\text { Body weight, body fat percentage, body fat mass, lean } \\
\text { body mass, weight, basal metabolic rate, water ratio, pro- } \\
\text { portion of lean body mass water, suggest that weight }\end{array}$ \\
\hline
\end{tabular}

Speed skating movement is the projects that take speed, strength as principles. Requiring athletes to correctly grasp the technology, reasonable distribution of physical strength, and has the capability of acceleration according to the state of play. Endurance quality of speed skating movement is especially important. Is the main anaerobic metabolism on athletes a mixture of metabolism? Through continuous load and intermittent load methods, improving the Max VO2, strengthening the sports ability of athletes, close to the under anaerobic threshold intensity aerobic training is the best strength, and can best improve the effect of aerobic endurance. Because of the speed skating training volume is larger; the athletes in training tend to consume a lot of energy, so the supplementation of speed skating project is especially important. Reasonable nutrition state is the material foundation to maintain good athletes training for the athletes' physical condition, has good effects on physical adaptation process and physical recovery after exercise and prevention of exercise-induced diseases. Reasonable nutrition can provide motion of appropriate energy material, to ensure good supply and utilization of energy material, the level of energy substances (glycogen) in the muscles also have direct relationship with the occurrence of sports injury. Reasonable nutrition can help recover after violent campaign, lessen the degree of fatigue or slow it. At the same time also can solve some special medical problems in sports training, such as weight control before the motility anemia and special sports nutrition of teenagers.

Athletes consumes a lot of calories and fat in trainings, protein accounts for about $12 \% \sim 15 \%$ of the total heat energy material, fat accounts for about $30 \%$, and carbohydrates for $55 \% \sim 70 \%$. In ensuring athletes meat, fish, poultry, egg, bean these high protein food, milk and milk products to absorb, should match healthy green food such as vegetables and fruits, cereals, rice flour and a moderate amount of grains), etc. It's not only necessary to ensure the nutrition balance and diversity, but also to require food concentration, volume weight as little as possible. In addition, arrange the distribution of the heat in food three meals a day according to the volume and duty; give full consideration to the athletes' digestive function of consumption and eating habits, etc., to ensure that athletes have abundant strength, to meet the competition and training better.

The trainings of speed skater have characteristics of long duration, no-intermittent and dynamic type. So athletes' diet should meet the following requirements: diet provides enough heat, recommended in meat meals outside increase $1 \sim 2$ times, which has helped to improve sports ability. But we should pay attention to consider that adds balance nutrition and nutrition density; Diet should provide sufficient protein, protein supply heat should reach $12 \% \sim 14 \%$ of total quantity of heat, should eat more red meat and milk. Diet should have the right amount of fat, fat can be $30 \% \sim 35 \%$ of total calories; Dietary carbohydrate calories in general should be $55 \%$ of the total heat energy, the intake should be increased to $60 \% \sim 70 \%$ before the training, and in order to improve the level of muscle glycogen; Should provide ironrich food to promote the synthesis of hemoglobin; Right amount of water and electrolyte should be added before competitions or trainings, and after the games and trainings should also be timely supplement; eating more food containing adequate vitamin $\mathrm{B}$ and $\mathrm{C}$ is also necessary.

\section{SCIENTIFIC TRAINING AND CONTROL OF BODY FAT}

Athletes' reducing weight means the athletes have a purpose, planned way to lose weight slowly in the process of long-term training (main body fat) at a lower level or within a short time before the process of rapid weight loss. According to the weight of speed reducing weight can be divided into two categories, namely fast weight and slow and weight 
reduction. Rapid weight reduction refers to the athlete weekly weight reduction rate is more than $4 \%$ of their body weight or short term weight reduction rate is greater than $1 \%$ of its own weight every day. Slow weight means the athletes weekly weight reduction rate is more than $2 \%$ of its own weight and less than $4 \%$ of its own weight. The athletes lose weight within a certain period of time, athletes in the scope of its weight in a certain range, under normal circumstances, the weekly volatility does not exceed $2 \%$ of its own weight, and this process is called control weight. The pre-match weight including slow weight and weight quickly, their goals are to lose weight. From the perspective of physiology, the slow weight reduction usually refers to the theory of negative heat balance, and to restrict energy intake increased energy expenditure or restrict the increase of energy intake and energy expenditure at the same time the methods (such as limiting diet, increasing sports or restricted diet combined with exercise), mainly in a long time by reducing body fat composition in the process of weight loss. The essence of which is mainly to reduce body fat, process generally slower, cycle is long. Rapid reducing weight usually refers to limit energy intake, dehydration by sharp or limit energy intake combining methods of dehydration, in a relatively short period of time mainly through reducing fat weight (mostly water) content in the process of weight loss. The essence is to reduce fat weight (mostly water), the process is generally faster, and shorter is cycle. For speed skaters, it is mainly related to the slow weight, namely the control of body fat.

\subsection{Establish the Ideal Weight Standards}

The key problem of athletes weight reduction is that finding the ideal weight, and determining the ideal body weight have the certain difficulty, but once established ideal weight or body fat, for whether you need to reduce weight or not right now, how much to reduce is the reference significance. At present, the athletes' ideal weight is often through the observation of the excellent athletes' body weight and body composition, and also gained from experience. Idea is: for the so-called ideal weight athletes' best weight: athletes achieve maximum strength, speed and endurance weight; Athletes won best ability at the minimum weight of body fat percentage. Ideal weight can not only be judged by subjective judgment, also cannot according to the physiological indexes to height and weight. Determination of body fat is to determine the ideal weight standards and achieving and maintaining a key problem in the process of ideal weight. Current research suggests that an ideal body fat percentage of athletes to determine the ideal weight are suitable of athletes. A certain amount of body fat is necessary to the body function; the coaches must be according to the player's height, body shape, body fat and weighing with the game time interval. Reducing Weight blindly cannot improve performance but will make its decline. So some scholars put forward that the suitable body fat percentage is wholesome, the minimum standard of men is $5 \%$, which of women shall not be less than $12 \%$. Less than $5 \%$ of the American college of sports medicine, the athlete body fat, should stop the game, when athletes under $7 \%$ body fat, can't lose body fat, at best, can only be limited to reduce the moisture inside body.
Determining the ideal body fat percentage can determine the ideal body weight, body fat and ideal is based on the excellent athletes or repeated observation and repeated test. Estimate athletes allowed to reduce body fat mass may refer to the following formula: the allowed reduction of body fat mass $=$ athletes existing weight $\mathrm{x}$ (existing body fat percentage - ideal body fat percentage). To estimate athletes ideal weight may refer to the following formula: ideal weight $=$ $100 \mathrm{x}$ the weight to fat weight $(\mathrm{kg})(100$ - ideal body fat \%), the judgment of the appropriate weight must consider the level of body fat. Sometimes athletes' weight is higher than that of normal persons in same age, but the low level of body fat, the fat and muscle to the high weight components. And muscle percentage was positively than with athlete's strength, so when the weight gain was due to muscle growth, no need to lose weight, but being overweight, high body fat percentage should be paid attention to when reducing weight.

\subsection{The Key to Control Weight--Reduce the Body Fat}

Fat free mass is the basis of the structure weight, once formed, it is stable, in theory, and think to the composition of fat weight is relatively constant. Children and adult body weight by $70 \% \sim 90 \%$ is made up of removal of the fat weight. In completing the process of growth and development of the adult, corrected age, gender, height, body weight change mainly reflects in the parts of body fat. The research shows that in the process of reducing weight must keep the fat free mass, because fat weight in the involved in metabolism, maintain skeletal muscle function and maintain organ function plays an important role, and suggests that in the process of reduce weight to fat weight loss does not exceed $30 \%$ of the total weight. Therefore, fat free mass is reduce weight must keep part of the process (especially the muscles, it is a dynamic source of movement), and fat weight is key part of the weight. When Athletes reducing weight, monitoring the body composition is very necessary, to remove excess body fat as much as possible, and to keep to fat weight, weight is the key to reduce body fat.

\subsection{Restrict Diets}

Restricted diet refers to the limit excessive intake of fat and sugar material, its essence is to limit intake of heat energy, resulting in heat energy negative balance, to achieve the objective of the consumption of body fat, reduce weight. Usually restrict the energy intake diet during $18 \sim 31 \mathrm{kcal} / \mathrm{kg}$ body weight / day [9], making daily heat energy shortfall during $1000 \sim 1500 \mathrm{kcal}$. Restricted diet weight can be divided into three stages: preparing the adaptation, namely small weight; The main weight reducing period; Consolidation phase, even if the falling weight no longer pick up. The duration of each stage can be arranged according to the training situation and specific requirements for weight reduction. Should not control drinking water too much during slow weight, daily intake should be kept in about $2500 \mathrm{ml}$, to ensure the excretion of metabolic product in body. Studies have shown that [ZACHWIEJAJJ et al., 2001], [BRYNER et al, 1999] [10], in pure limit energy intake decrease body fat can reduce weight, fat weight or muscle at the same time the quality will also drop, depends on the degree of reducing calorie restriction of rigor. But from the perspective of the 
impact on the performance of moderate and restricted diet is desirable.

\subsection{Adjust the Exercise Load}

Besides negative balance of heat energy in addition to reducing heat energy intake, increase the body's heat energy consumption is another way. Movement provides a way of increasing energy consumption; it can help to adjust the weight when the energy balances. At least $30 \mathrm{~min}$ a day of moderate intensity aerobic exercise helps to reduce the weight and greater amounts of exercise for weight loss effect is better. Increasing movement is an important part of the slow weight, a large number of studies have shown that regular exercise is good for losing weight. Aerobic exercise can directly affect the energy balance, promote adipose decompose power decrease body fat; Resistance exercise stimulate the nerve-endocrine system, and promote the muscle protein synthesis, helps to keep fat weight, at the same time, by increasing its basal metabolic rate and improve the fat oxidation to have certain influence on weight [MELBYCC et al., 1993]. Combine aerobic exercise with strength training, the overall effect is weight loss, at the same time is body composition promoting, body fat percentage decline, remaining the same or higher fat weight, and it is the preferred movement combination of control weight and keep fat free mass.

\subsection{Restrict Diets Combined with Increased Movement}

Slow reduction of weight of all the best plans, should be selective consumption of body fat, at the same time maintain unchanged to fat weight; For athletes, another concern is to maintain their sports ability; Rely on energy limit weight usually lead to a significant number of weight loss, but combined with aerobic exercise will often reduce the lost. Resistance to fat during exercise can prevent limit energy intake weight loss, and even increase muscle weight Limit energy intake at the same time combined with exercise can reduce the negative effect on the sport ability. Enough strength and amount of aerobic exercise, even during the period of strict limit energy intake can improve the ability of aerobic exercise, while the resistance movement to lose weight at the same time increase muscle mass and strength. Increase exercise combined with a restricted diet weight can make diet limits on energy intake broaden, avoid the limit of predatory weight alone to fat weight loss caused by the adverse consequences, while retaining the advantages of the motion to reduce weight. Combination of both, to support the reasonable diet and nutrition, is the preferred method of slow reduction of weight for athletes.

\section{WEIGHT CONTROL PRINCIPLES AND NOTES}

Only in realistic target weight, weight control measures during the proper and reasonable rate and weight control diet nutrition guarantee under the premise of can achieve results. Agent is an advanced computing, if we compare with the traditional numerical analysis method. It not only provides modeling methods, but also gives solution of the problem. In particular, agent-oriented system may deal with complex interactions between environment and the robot. Now more and more people think that the intelligence of robot is increased in these interactions.

During weight control training athletes should not only finish the training such as tactics, but also control weight through a variety of measures. To do well in this period of function, evaluation of athletes and the dietary, nutrition monitoring work, and giving timely feedback by the evaluation and monitoring results for the coaches, providing a reference for control during weight training, nutrition, and facilitating the coach for the next step of arrangement and adjustment. Athletes in the weight of the specific situation are not the same, suitable for an athlete method measure of another player does not necessarily fit every athlete to for their own actions. Athletes choose weight range should be determined according to the athlete's body fat percentage. When athletes choose specific measures in the process of reducing weight also there are age and gender differences. Sportsman's weight reduction rate, weight of detailed nutrition plan must be formulated according to the actual circumstances of the athletes. Reducing weight should be moderate, should not be too great weight range, when athletes body fat content is below 7\%, will no longer lose fat, will only have to reduce the moisture inside body. Otherwise it will greatly affect the athletes' athletic ability and health, is not conducive to its best performance. In addition, the control of weight should be stability, not upset down

\section{MATERIAL AND METHODS}

Athletes control body fat is complicated system engineering, its success or failure depends on many links: coaches, the scientific research personnel, athletes, knowledge acquisition and understanding to control weight, the choice of means of weight control and execution, control weight training athletes dietary nutrition support, and so on. Only under the premise of the regaining the weight of relevant knowledge and understanding it, choosing the right means and executing it, and under the reasonable nutrition support can we obtain reasonable success of body fat.

How to scientifically and reasonably control body fat, in order not to harm the athletes physical health and reduce the ability to work under the premise of achieving anticipated goal of reducing weight, is a problem of sports science research and sports training practice need to be solved. Research group identify athletes ideal weight through the study of how to determine the ideal weight diagnostic indicators of athletes, how to develop suitable for elite athletes individuals charged with weight of the best course of action and nutrient solution, the scientific and meticulous research has been clear about the use of the combination of sports nutrition and scientific training monitoring body fat, but in the rapid development of science and technology today, a lot of problems and solutions are constantly changing and developing, it needs we sport workers to constantly learn and progress, and solve new problems in future practices and researches.

\section{CONFLICT OF INTEREST}

The authors confirm that this article content has no conflict of interest. 


\section{ACKNOWLEDGEMENT}

This work is supported by the Key Project of Guangxi Social Sciences, China (No.gxsk201424), the Education Science fund of the Education Department of Guangxi, China (No.2014JGA268), and Guangxi Office for Education Sciences Planning, China (No.2013C108).

\section{REFERENCES}

[1] Z. Yang, "The research progress of sports nutrition biological chemistry," Chinese Journal of Sports Medicine, vol. 23, pp. 158$165,2004$.

[2] L. Feng, M. Feng, and W. Feng, "Evaluation method of excellent athletes' body function," People's Sport Publishing House, pp. 311- 325, 2003.

[3] J. Chen, "Sports Nutrition," Beijing: Beijing Medical University press, vol.8, 2002

[4] W. Gang, "Athletes dietary nutrition survey," Journal of Ice and Snow Sports, no.2, pp.33-34, 2001.
[5] L. X. Shang, Z. Yang, and H. Yan, "The 19th Olympic winter games the national short track speed skating athletes dietary nutrition survey and body composition analysis," Journal of Ice and Snow Sports, no.5, pp. 628, 2004.

[6] L. Yan, G. Liu, and B. Mi, "National speed skating team short group for the 20th Olympic winter games and scientific research summary," Journal of Ice and Snow Sports, no.2, pp. 123, 2006.

[7] J. Wang, "Sports nutrition solutions," J. of Track and Field, no.6, pp. $54-56,2005$

[8] M. Fogelholm, "Effects of body weigh t reduction on sports performance," Sports Med, vol.18, no. 4, pp. 249-267, 1994.

[9] J.J. Zachwieja, D.M. Ezell, A.D. Cline, J.C. Ricketts, P.C. Vicknair, S.M. Schorle, and D.H. Ryan, "Short - term dietary energy restriction reduces lean body mass but not performance in physically active men and women," Int J Sports Med, vol. 22, no. 4, pp.310-316, 2001

[10] R. W. Bryner, I. H, Ulrich, J. Sauers, D. Donley, G. Hornsby, M. Kolar, and R. Yeater, "Effects of resistancevs. aerobic training combined with an 800 calorie liquid diet on lean body mass and resting metabolic rate," J. Am Coll Nutr, vol. 18, no. 2, pp. 115121, 1999.

Received: June 10, 2015

Revised: July 29, 2015

Accepted: August 15, 2015

(C) Yuchun Huang; Licensee Bentham Open.

This is an open access article licensed under the terms of the (https://creativecommons.org/licenses/by/4.0/legalcode), which permits unrestricted, noncommercial use, distribution and reproduction in any medium, provided the work is properly cited. 